Vol 13, Issue 9, 2020

\title{
KNOWLEDGE, ATTITUDES, AND PRACTICES TOWARDS COVID-19 AMONG RESIDENTS IN HAIL CITY, SAUDI ARABIA: A CROSS-SECTIONAL STUDY
}

\author{
FARHAN ALSHAMMARI ${ }^{1 *}$, TURKI ALHAGBANI ${ }^{1}$, AHMED ALAFNAN ${ }^{2}$, KHALID ALMANSOUR $^{1}$, \\ KASHIFULLAH KHAN ${ }^{3}$
}

${ }^{1}$ Department of Pharmaceutics, College of Pharmacy, University of Hail, Hail, Saudi Arabia. ${ }^{2}$ Department of Pharmacology and Toxicology, College of Pharmacy, University of Hail, Hail, Saudi Arabia. ${ }^{3}$ Department of Clinical Pharmacy, College of Pharmacy, University of Hail, Hail, Saudi Arabia. Email: frh.alshammari@uoh.edu.sa

Received: 05 June 2020, Revised and Accepted: 06 July 2020

ABSTRACT

Objective: Immense measures were taken to monitor the rapid spread of the novel coronavirus disease (COVID-19) outbreak in Saudi Arabia. Knowledge, attitudes, and practices (KAPs) against COVID-19 influence a resident's commitment to these control measures. The objective of the study was to investigate the KAP of Saudi residents toward COVID-19 during the increasingly growing outbreak period.

Methods: Through the authors' network with residents in Hail city and the northern region of Saudi Arabia, an online sample was successfully carried out among Saudi residents. The participants completed an established and validated online KAP questionnaire. The knowledge questionnaire consisted of 16 questions regarding the clinical characteristics and prevention of COVID-19. Assessments of attitudes and practices of the residents toward COVID-19, included questions on confidence in controlling the COVID-19 outbreak, going to crowded places and wearing facemasks when going out in recent days.

Results: A total of 285 participants took part in the survey questionnaire, of these $54.7 \%$ were women, $68.4 \%$ held a bachelor's degree, and $47.7 \%$ were engaged in an occupation other than health-care providers. The overall correct rate of the knowledge questionnaire was $65 \%$. The majority of the respondents (66\%) reported that they had confirmed the information obtained from different media sources, where nearly $78.3 \%$ of respondents agreed that COVID-19 can be successfully controlled. Furthermore, about $92.3 \%$ of the participants avoided going out to crowded places, whereas only $41.1 \%$ wore facemasks when going out in recent days. A statistically significant association ( $p=0.0001)$ was found on analysis of the COVID-19 knowledge score, with a lower likelihood of negative attitudes and preventive practices toward COVID-2019.

Conclusion: The majority of Hail city residents are familiar with COVID-19 in both genders, hold optimistic attitudes, and have appropriate practices toward COVID-19. Health education programs designed to enhance COVID-19 awareness are beneficial for Saudi residents to maintain positive attitudes and appropriate practices.

Keywords: Knowledge, Attitude, Practice, COVID-19, Saudi Arabia.

(C) 2020 The Authors. Published by Innovare Academic Sciences Pvt Ltd. This is an open access article under the CC BY license (http://creativecommons. org/licenses/by/4. 0/) DOI: http://dx.doi.org/10.22159/ajpcr.2020.v13i9.38630

\section{INTRODUCTION}

By the end of 2019, there were cases of pneumonia caused by an unknown pathogen in Hubei Province in China [1-3]. The clinical manifestations of these cases were dry cough, shortness of breath, high fever, and pulmonary dysfunction in some cases. All cases were related to the Wuhan wholesale animal market. The causative pathogen was identified from samples of throat swabs on and later called severe acute respiratory syndrome coronavirus 2. However, the disease was named novel coronavirus disease (COVID-19) by the World Health Organization (WHO) [4].

On March 12, 2020, the WHO declared COVID-19 outbreak is a pandemic, yet, the first COVID-19 case in Saudi Arabia was announced on the March 2, 2020 [5]. Since then, the Saudi government has been taking stringent measures to control the pandemic. On March 4, 2020, the Saudi government declared a temporary suspension of Umrah as a protective measure against COVID-19 [6]. Furthermore, the Saudi government decided to suspend schools and universities on March 8, 2020, over COVID-19 fears [7]. These actions were followed by announcing partial curfew that took place on March 23, 2020, in all the 13 administrative regions in Saudi Arabia followed by compulsory travel restrictions between these 13 regions $[8,9]$. More stringent measures were also imposed with declaring $24 \mathrm{~h}$ curfew in the hot zones in Saudi Arabia such as Riyadh, Jeddah, and other cities. This curfew was based on evidence that social distancing between people will result in slowing down the COVID-19 virus transmission $[9,10]$.
The combat of COVID-19 must be continued to assure its ultimate success. Failure to follow the governmental guidelines during the current pandemic can put public health at risk. Therefore, people's compliance with government directions is critical and is significantly affected by public knowledge and attitudes toward COVID-19. Therefore, if the public has adequate and accurate knowledge along with proper recommendations from local health authorities about the COVID-19 pandemic, they are more likely to follow the recommendations and realize that seriousness of following these recommendations, which eventually will result in preventing the spread of the pandemic, while a failure to follow the recommendations will have catastrophic consequences $[11,12]$.

Hail city is located in the north of the Kingdom of Saudi Arabia. The population of Hail city is estimated to be 356,770 Saudi nationals and expatriates [13]. The Saudi government representative from the health ministry declared that both nationals and expatriates - including illegal residents - will receive free health-care services during the pandemic. Rationale of the current study is that until the time when this study was completed, Hail city had not registered any positive COVID-19 cases. However, to help in maintaining the control of COVID-19 outbreaks in Hail city, it is important to understand public awareness of COVID-19 during this crucial time. To the best of our knowledge, no studies have been conducted in the Hail region to analyze this topic which justify the novelty of the current study. Therefore, we studied the knowledge and 
attitudes of the population of Hail city toward COVID-19 during the $1^{\text {st }}$ month of the COVID-19 outbreak in Saudi Arabia.

\section{METHODS}

\section{Participants}

This survey was performed from April 8 to April 12, during the $1^{\text {st }}$ week of the prolonged curfew period that took place in Hail city, Saudi Arabia. This study was conducted through an online-based survey due to the implementation of the social distancing policy during that period and a convenient sampling method was used for the collection of sample size. Permission was granted from the authors of a similar study conducted in Wuhan, Hubei Province, China, to use the same questionnaire that they had used with minor amendments where the Cronbach's alpha coefficient of the knowledge questionnaire was 0.71 in our sample, indicating acceptable internal consistency $[14,15]$. An electronic link of the questionnaire was distributed through social media groups such as WhatsApp and Twitter accounts. This link contains a brief introduction to the background, purpose, voluntary participation, privacy of data, and notes to complete the questionnaire. Saudi citizens aged 18 and older who agreed to participate in the study were invited to complete the survey. The protocol of this study was approved by the Research Ethics Committee at the University of Hail beforehand.

\section{Measures}

The survey questionnaire comprised demographic characteristics and knowledge, attitudes, and practices (KAPs) section (Table 1). The demographic characteristics include gender, age, marital status, education status, occupation, and city of residence. The questionnaire had 16 questions (Table 1), where K1-K4 were related to the clinical manifestations of COVID-19, K5-K7 to the transmission mode, and K8K16 to COVID-19 prevention and control. In the knowledge part, each statement (K1-K16) has three options to choose from, true, false, or I do not know. Questions that were answered correctly were scored with 1 point while those which were answered wrongly or in case of choosing "I don't know" option were scored 0 . The total knowledge score scale for each participant ranged from 0 to 16 . The higher the score, the more knowledge of the participant toward COVID-19, while lower scores represent the opposite. On the other hand, attitudes (A) and practices (P) toward COVID-19 were measured by three questions (A1-A3) and two questions (P1-P2), respectively (Table 1).

\section{Statistical analysis}

Correct knowledge answer frequencies, various types of attitudes, and practices were identified. Knowledge scores, attitudes, and practices of each participant were compared, based on their demographic characteristics, with independent t-test, one-way ANOVA, or Chi-square test as needed. Multivariable linear regression analysis was performed to classify factors correlated with knowledge by utilizing all the demographic variables as independent variables while knowledge scores as the outcome variables. The dummy variables were set in multiple linear regression on factors associated with COVID-19 knowledge when comparing knowledge scores between populations holding different attitudes toward COVID-19. Likewise, binary logistic regression has been performed to classify variables related to attitudes and practices. To quantify the association between variables and KAP, unstandardized

Table 1: Questionnaire of public knowledge toward COVID-19

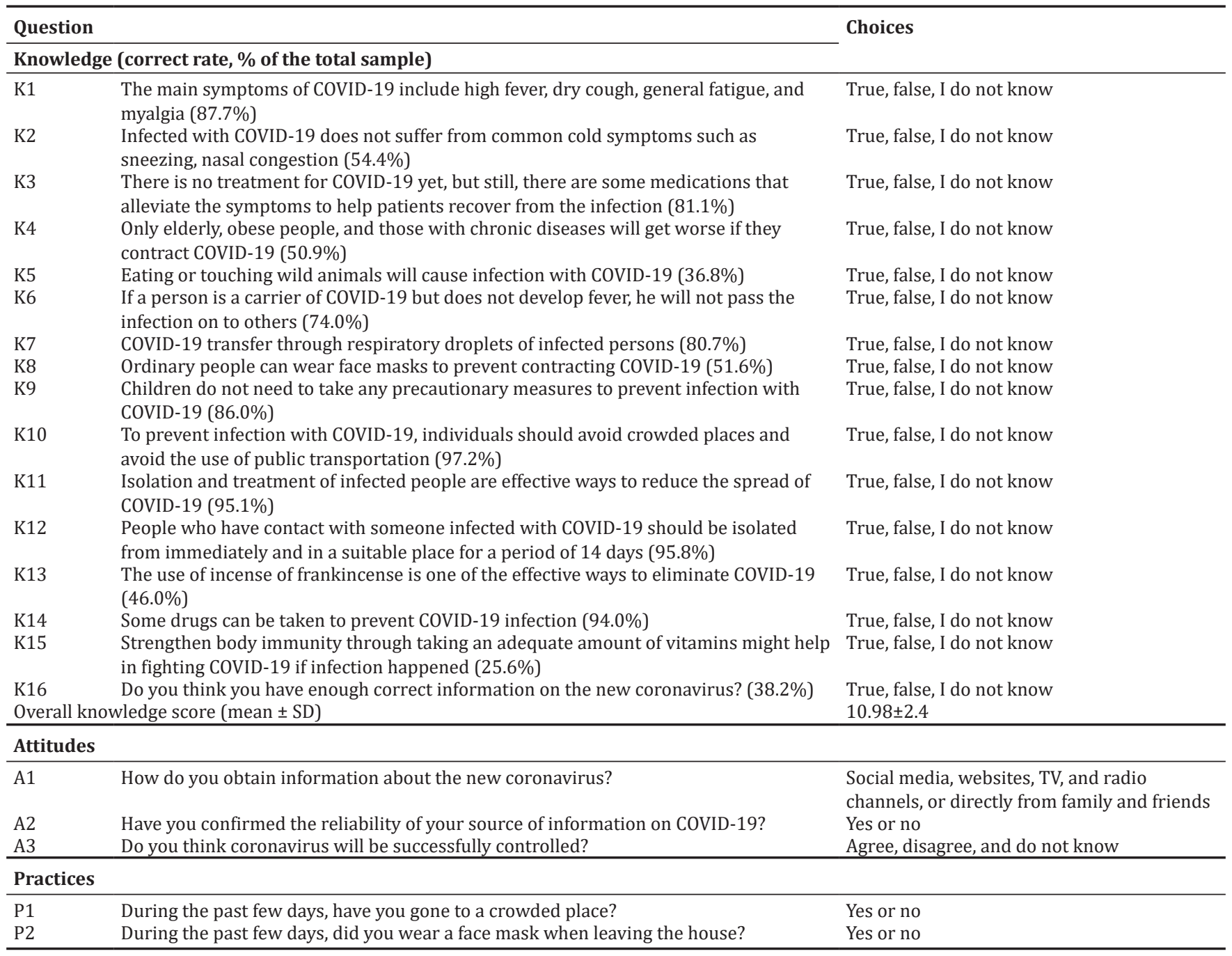


regression coefficients ( $\beta$ ) and odds ratios with $95 \%$ confidence intervals (CIs) were used with the aid of SPSS version 22.0 for data analysis, where the degree of statistical significance was set at $0.05(\mathrm{p}<0.05)$.

\section{RESULTS}

A total of 285 participants completed the survey questionnaire successfully. Among this final sample, majority of the participants 134 (47\%) were aged between 18 and 29 years, 156 (54.7.7\%) were female, 160 (56.1\%) were married, and 195 (68.4\%) of the participants held a bachelor's degree. The majority of the participants, 194 (68.1\%), are employed out of which 58 (20.4\%) were health-care professionals, and 197 (69.1\%) were Hail residents (Table 2). The range of the correct answers of the 16 questions for the knowledge part of COVID-19 was 25.6-97.2\% (Table 1). The mean COVID-19 knowledge score was 10.98 with a standard deviation of \pm 2.4 . The knowledge scores of the participants were differed significantly, with $p<0.05$ across genders $(p \leq 0.001)$, age groups $(p=0.049)$, education status $(\mathrm{p} \leq 0.0001)$, and occupation $(\mathrm{p}=0.003)$ (Table 2$)$.

Multiple linear regression was performed in which the knowledge score was taken as a dependent while age, marital status, education status, occupation, and place of residence were taken as an independent. The findings of multiple linear regression showed that the male gender with a $\beta:-0.184 ; 95 \% \mathrm{CI}:-1.258,-0.222(\mathrm{p}=0.005)$ was significantly associated with lower knowledge score in comparison with females. However, the results showed an increase in the knowledge score associated with the education level of the participants. The knowledge score significantly increased with $\beta: 0.193 ; 95 \% \mathrm{CI}: 0.256,1.080$ with $\mathrm{p}=0.002$, as shown in Table 3 .

In the attitude section, the source of information aboutCOVID-19 obtained by participants (A1) showed that the majority of the participants, 141 (49.5\%), obtained their information from social media followed by 72 participants (25.3\%) by websites and 66 participants (23.1\%) from TV or radio, respectively, as shown in Fig. 1. For the confirmation of information

Table 2: Demographic variables of participants and knowledge score by variables

\begin{tabular}{|c|c|c|c|}
\hline Variable & n (\%) & $\begin{array}{l}\text { Knowledge } \\
\text { score } \\
\text { (Mean } \pm S D)\end{array}$ & p-value \\
\hline \multicolumn{4}{|l|}{ Gender } \\
\hline Female & $156(54.7)$ & $11.4 \pm 2.1$ & \multirow{2}{*}{$<0.001^{* a}$} \\
\hline Male & $129(45.3)$ & $10.4 \pm 2.6$ & \\
\hline \multicolumn{4}{|c|}{ - } \\
\hline $18-29$ years & $134(47)$ & $10.6 \pm 2.6$ & \multirow[t]{4}{*}{$0.049 * \mathrm{~b}$} \\
\hline 30-39 years & $107(37.5)$ & $11.2 \pm 2.3$ & \\
\hline $40-49$ years & $35(12.3)$ & $11.5 \pm 1.9$ & \\
\hline 50 years and above & $9(3.2)$ & $11.8 \pm 1.6$ & \\
\hline \multicolumn{4}{|l|}{ Marital status } \\
\hline Single & $115(40.4)$ & $10.7 \pm 2.6$ & \multirow[t]{3}{*}{$0.124^{\mathrm{b}}$} \\
\hline Married & $160(56.1)$ & $11.2 \pm 2.1$ & \\
\hline Divorced/widowed & $10(3.5)$ & $10.3 \pm 2.9$ & \\
\hline \multicolumn{4}{|l|}{ Education status } \\
\hline Middle school and below & $4(1.4)$ & $8.8 \pm 3.9$ & \multirow[t]{4}{*}{$<0.0001^{* \mathrm{~b}}$} \\
\hline High school & $61(21.4)$ & $10.1 \pm 2.6$ & \\
\hline Bachelor's degree & $195(68.4)$ & $11.0 \pm 2.2$ & \\
\hline MSc and higher & $25(8.8)$ & $12.5 \pm 1.4$ & \\
\hline \multicolumn{4}{|l|}{ Occupation } \\
\hline Student & $43(15.1)$ & $10.6 \pm 2.2$ & \multirow[t]{5}{*}{$0.003^{* b}$} \\
\hline Housewife & $18(6.3)$ & $10.3 \pm 2.8$ & \\
\hline Unemployed & $30(10.5)$ & $10.2 \pm 2.5$ & \\
\hline $\begin{array}{l}\text { Employed (health-care } \\
\text { provider) }\end{array}$ & $58(20.4)$ & $11.9 \pm 1.6$ & \\
\hline Employed (other**) & $136(47.7)$ & $10.9 \pm 2.5$ & \\
\hline \multicolumn{4}{|l|}{ City of residence } \\
\hline Hail & 197 (69.1) & $10.9 \pm 2.3$ & \multirow[t]{2}{*}{$0.821^{\mathrm{a}}$} \\
\hline Other & $88(30.9)$ & $11.0 \pm 2.5$ & \\
\hline
\end{tabular}

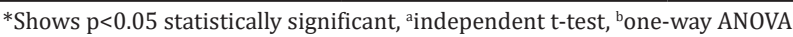

**Any profession other than health-care providers obtained from different sources (A2) (as mentioned in Fig. 1), findings indicated that 188 out of 285 participants $(66.0 \%)$ had confirmed the information, which they obtained from different sources.

Regarding the attitude of participants toward COVID-19, for question (A3), "Do you think Coronavirus will be successfully controlled?" 117 $(75 \%)$ of female participants agreed, and similarly, in participants with 18-29 years of age and married cohort, most of the participants agreed, with 104 (77.6\%), and 122 (76.3\%), respectively. Furthermore, concerning educational status, $154(79 \%)$ participants holding a bachelor's degree, 101 (74.3\%) participants employed in an occupation other than health care, and 151 (76.6\%) participants residing in Hail city responded, "agree" to the question (A3) related to attitude toward COVID-19 (Table 4). On the other hand, participants who responded "Disagree" and "Don't know" had lower knowledge scores compared to participants who responded "Agree" (Table 4). A multiple logistic regression analysis was performed by assigning responses "Agree"

Table 3: Results of multiple linear regression on factors associated with COVID-19 knowledge

\begin{tabular}{lllll}
\hline Variable & $\boldsymbol{\beta}$ coefficient & $\boldsymbol{p}$-value & \multicolumn{2}{c}{$\mathbf{9 5 \%} \mathbf{C I}$} \\
\cline { 3 - 5 } & & & Lower & Upper \\
\hline Gender & $-0.184^{*}$ & 0.005 & -1.258 & -0.222 \\
Age & 0.082 & 0.244 & -0.140 & 0.550 \\
Marital status & -0.027 & 0.695 & -0.488 & 0.326 \\
Education status & $0.193^{*}$ & 0.002 & 0.256 & 1.080 \\
Occupation & 0.038 & 0.590 & -0.139 & 0.244 \\
Place of residence & 0.011 & 0.855 & -0.459 & 0.553 \\
\hline
\end{tabular}

Multiple linear regression used ref: Gender: Female, marital status: Single,

education status: Middle school and below, occupation: Student and place of

residence: Hail; CI: Confidence interval; *shows $\mathrm{p}<0.05$ statistically significant

Table 4: Attitudes toward COVID-19 by demographic variables

\begin{tabular}{|c|c|c|c|}
\hline \multirow[t]{2}{*}{ Variable } & \multicolumn{3}{|c|}{ Attitudes, n (\%) } \\
\hline & Agree & Disagree & Do not know \\
\hline \multicolumn{4}{|l|}{ Gender } \\
\hline Female & $117(75.0)$ & $4(2.6)$ & $35(22.4)^{*}$ \\
\hline Male & $101(78.3)$ & $5(3.9)$ & $23(17.8)$ \\
\hline \multicolumn{4}{|l|}{ Age } \\
\hline $18-29$ years & $104(77.6)$ & $5(3.7)$ & 25 (18.7) \\
\hline 30-39 years & $80(74.8)$ & $4(3.7)$ & $23(21.5)$ \\
\hline $40-49$ years & $29(82.9)$ & 0 & $6(17.1)$ \\
\hline 50 years and above & $5(55.6)$ & 0 & $4(44.4)$ \\
\hline \multicolumn{4}{|l|}{ Marital status } \\
\hline Single & $9(5.2)$ & $91(79.1)$ & $18(15.7)$ \\
\hline Married & $122(76.3)$ & $3(1.9)$ & 35 (21.9) \\
\hline Divorced/widowed & $5(50.0)$ & 0 & $5(50.5)$ \\
\hline \multicolumn{4}{|l|}{ Education status } \\
\hline $\begin{array}{l}\text { Middle school and } \\
\text { below }\end{array}$ & $2(50.0)$ & 0 & $2(50.0)$ \\
\hline High school & $44(72.1)$ & $2(3.3)$ & $15(24.6)$ \\
\hline Bachelor's degree & $154(79.0)$ & $6(3.1)$ & 35 (17.9) \\
\hline MSc and higher & $18(72.0)$ & $1(4.0)$ & $6(24.0)^{*}$ \\
\hline \multicolumn{4}{|l|}{ Occupation } \\
\hline Student & $35(81.4)$ & $3(7.0)$ & $5(11.6)$ \\
\hline Housewife & $14(77.8)$ & 0 & $4(22.2)$ \\
\hline Unemployed & $24(80.0)$ & $2(6.7)$ & $4(13.3)$ \\
\hline $\begin{array}{l}\text { Employed (health-care } \\
\text { provider) }\end{array}$ & $44(75.9)$ & $1(1.7)$ & $13(22.4)$ \\
\hline Employed (other**) & $101(74.3)$ & $3(2.2)$ & $32(23.5)$ \\
\hline \multicolumn{4}{|l|}{ City of residence } \\
\hline Hail & $151(76.6)$ & $5(2.5)$ & $41(20.8)$ \\
\hline Other & $67(76.1)$ & $4(4.5)$ & 17 (19.3) \\
\hline $\begin{array}{l}\text { Knowledge score } \\
(\text { mean } \pm S D)\end{array}$ & $11.0 \pm 2.3$ & $10.4 \pm 3.3$ & $10.8 \pm 2.5^{* *}$ \\
\hline
\end{tabular}

${ }^{* *}$ Others: Employed other than health-care providers. Significant $\mathrm{p}$ values: ${ }^{*} \mathrm{p}<0.05,{ }^{* *} \mathrm{p}<0.01$ 
and "Disagree," and the findings showed that none of the factors was statistically associated with disagreement on the final success in controlling the pandemic (Table 5).

The practice section showed that the majority of the participants responding to questions (P1) revealed that they had not visited crowded places in recent days; however, a majority of the participants did not also wear facemasks when they have left their houses (Table 6). Multiple logistic regression analysis was performed, and the findings revealed no statistically significant $(p>0.05)$ association with going to any crowded place and wearing a facemask outside.

\section{DISCUSSION}

To the best of our knowledge, this is the first study in the Kingdom of Saudi Arabia evaluating Saudi residents KAP toward COVID-19. Among the population, where most of the respondents were well educated, having bachelor's and master's qualification, we found an overall correct rate of nearly $65 \%$ on the knowledge questionnaire, indicating that most respondents are knowledgeable about COVID-19.

The majority of the respondents who participated in this study also held an optimistic attitude toward the COVID-19 pandemic, where approximately $75 \%$ of the participants believed that COVID-19 will finally be successfully controlled, and $66 \%$ of participants reported that they had confirmed the reliability of the information they obtained from different sources. Despite this, the practices of Hail city residents indicated that they were very careful to avoid problems and dangers: Nearly, all participants avoided going to crowded places (86.8\%), although a majority of the participants are careless to wear face masks when leaving their home $(60.2 \%)$ during the rapid rise period of the COVID-19 outbreak.

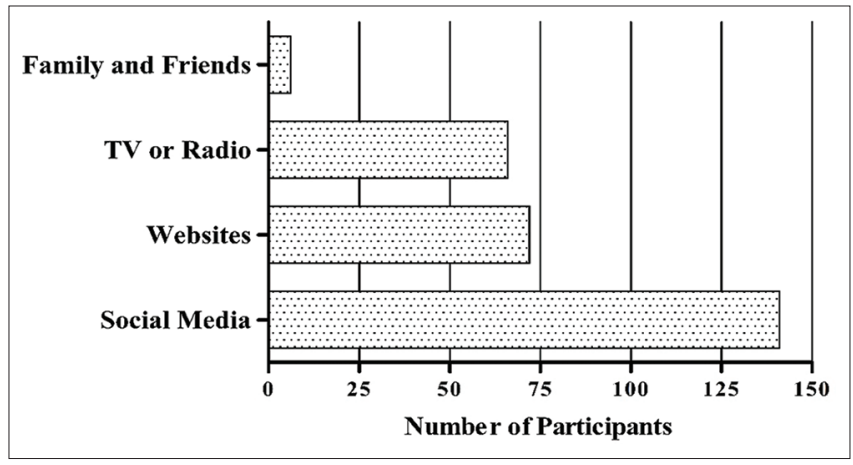

Fig. 1: Source of information obtained about COVID-19 by participants
In the current study, we analyzed the characteristics of KAP toward COVID-19 and determined some demographic factors correlated with KAP, which, in turn, will aid public health policy-makers and health care workers to recognize target populations for COVID-19 prevention programs and more health education. Because the COVID-19 outbreak was in its very early stages during this current epidemiological survey, it was believed that the results were unlikely to show a high correct rate of COVID-19 knowledge in Hail city residents. We acknowledge that the surprisingly high rate of the respondents' knowledge is primarily due to the sample characteristics, where $77.2 \%$ of the study sample held a bachelor's and master's degree or higher, and $21.4 \%$ have at least high school education. Because of the severe situation of the epidemic and the staggering news reports about this public health emergency, it is not surprising that the public would actively seek knowledge of COVID-19 from various channels of information such as the official website of the Ministry Of Health (MOH) of Saudi Arabia, where most of the educational material (e.g., brochures) are posted online. However, caution must be exercised when using social media as the main source of information. Moreover, there is also a continuous delivery of information and precautionary measures for controlling the COVID-19 pandemic, through mobile phone technologies to the residents. This speculation supports the significant positive association between levels of education and COVID-19 knowledge scores.

During the Middle East respiratory syndrome-related coronavirus (MERS-COV) epidemic, $40-52 \%$ of the Saudi populations believed that MERS-COV could be successfully controlled or prevented by the governmental institutions [16], while another study revealed that almost $97 \%$ of the participants believed that MERS-COV could be successfully controlled [17]. These figures are almost similar to our findings on the rates of final success in controlling the COVID-19 epidemic. The promising and confident attitude of the Saudi population could be related to the tremendous COVID-19 control measures that have been applied strictly throughout the Kingdom of Saudi Arabia cities, such as traffic limits in all cities and the shutdown of various "hot zone cities" such as the regional capitals, and the cities of the two holy mosques, while the different regions were partially in lockdown during daytime and completely lockdown in the evenings and at night. These kinds of control measures consolidate the resident's confidence in the determination of the government to control the virus outbreak. Furthermore, the planned and collaborative efforts across the country provinces also upsurge Saudi people's confidence to overcome the epidemic. The majority of the provinces had been equipped with thousands of medical workers and materials to aid the COVID-19 virus control efforts.

However, from the current study results, attitudes toward COVID-19 were highly encouraged, as most residents took precautions to

Table 5: Results of multiple binary logistic regression analysis on factors significantly associated with attitudes toward COVID-19

\begin{tabular}{lllll}
\hline Variable & Odds ratio & p-value & 95\% CI & \\
\cline { 3 - 5 } & & & Lower & Upper \\
\hline Gender (female vs. male) & & 0.190 & 0.303 & 1.267 \\
Age (18-29 years vs. 30-39 years) & 0.619 & 0.806 & 0.248 & 6.011 \\
Age (18-29 years vs. 40-49 years) & 1.221 & 0.665 & 0.307 & 6.361 \\
Age (18-29 years vs. 50 and above) & 1.398 & 0.241 & 0.508 & 14.832 \\
Marital status (single vs. married) & 2.745 & 0.175 & 0.626 & 13.208 \\
Marital status (single vs. divorced/widowed) & 2.875 & 0.173 & 0.649 & 11.056 \\
Education status (middle school and below vs. high school) & 0.232 & 0.264 & 0.018 & 3.013 \\
Education status (middle school and below vs. bachelor) & 0.672 & 0.506 & 0.208 & 2.169 \\
Education status (middle school and below vs. M.Sc. and above) & 1.099 & 0.856 & 0.395 & 3.060 \\
Employment status (student vs. housewife) & 2.130 & 0.194 & 0.680 & 6.672 \\
Employment status (student vs. unemployed) & 2.563 & 0.219 & 0.571 & 11.494 \\
Employment status (student vs. health care) & 1.664 & 0.355 & 0.566 & 4.896 \\
Employment status (student vs. other than health care) & 1.395 & 0.438 & 0.602 & 3.232 \\
Place residence (Hail vs. other) & 0.921 & 0.803 & 0.480 & 1.767 \\
\hline
\end{tabular}

Multiple logistic regression was performed, $\mathrm{p}<0.05$ was considered statistically significant 
Table 6: Practices toward COVID-19 by demographic variables

\begin{tabular}{|c|c|c|c|c|}
\hline \multirow[t]{3}{*}{ Variable } & \multicolumn{4}{|c|}{ Practices, n (\%) } \\
\hline & \multicolumn{2}{|c|}{ Going to a crowded place } & \multicolumn{2}{|c|}{ Wearing a face mask } \\
\hline & Yes & No & Yes & No \\
\hline \multicolumn{5}{|l|}{ Gender } \\
\hline Female & $12(7.7)$ & $144(92.3)$ & $60(38.5)$ & $96(61.5)$ \\
\hline Male & $24(18.6)$ & $105(81.4)$ & $53(41.1)$ & $76(58.9)$ \\
\hline \multicolumn{5}{|l|}{ Age } \\
\hline $18-29$ years & $18(13.4)$ & $116(86.6)$ & $58(43.3)$ & $76(56.7)$ \\
\hline $30-39$ years & $13(12.1)$ & $94(87.9)$ & $40(37.4)$ & $67(62.6)$ \\
\hline $40-49$ years & $5(14.3)$ & $30(85.7)$ & $13(37.1)$ & $22(62.9)$ \\
\hline 50 years and above & 0 & $9(100.0)$ & $2(22.2)$ & 7 (77.8) \\
\hline \multicolumn{5}{|l|}{ Marital status } \\
\hline Single & $17(14.8)$ & $98(85.2)$ & $49(42.6)$ & $66(57.4)$ \\
\hline Married & 17 (10.6) & $143(89.4)$ & $59(36.9)$ & $101(63.1)$ \\
\hline Divorced/widowed & $2(20.0)$ & $8(80.0)$ & $5(50.0)$ & $5(50.0)$ \\
\hline \multicolumn{5}{|l|}{ Education } \\
\hline Middle school and below & 0 & $4(100.0)$ & $2(50.0)$ & $2(50.0)$ \\
\hline High school & $12(19.7)$ & $49(80.3)$ & $29(47.5)$ & $32(52.5)$ \\
\hline Bachelor's degree & $23(11.8)$ & $172(88.2)$ & $75(38.5)$ & $120(61.5)$ \\
\hline MSc and higher & $1(4.0)$ & $24(96.0)$ & $7(28.0)$ & $18(72.0)$ \\
\hline \multicolumn{5}{|l|}{ Occupation } \\
\hline Student & $2(4.7)$ & $41(95.3)$ & $18(41.9)$ & $25(58.1)$ \\
\hline Housewife & 0 & $18(100.0)$ & $7(38.9)$ & $11(61.1)$ \\
\hline Unemployed & $4(13.3)$ & $26(86.7)$ & $12(40.0)$ & $18(60.0)$ \\
\hline Employed (health-care provider) & $8(13.8)$ & $50(86.2)$ & $20(34.5)$ & $38(65.5)$ \\
\hline Employed (other*) & $22(16.2)$ & $114(83.8)$ & $56(41.2)$ & $80(58.8)$ \\
\hline \multicolumn{5}{|l|}{ City of residence } \\
\hline Hail & 25 (12.7) & 172 (87.3) & 77 (39.1) & 120 (60.9) \\
\hline Other & $11(12.5)$ & 77 (87.5) & $36(40.9)$ & $52(59.1)$ \\
\hline
\end{tabular}

*Others: Employed other than health-care providers

prevent COVID-19 infection by not going to crowded places. These stern protective practices could be primarily associated with the very rigorous prevention and control measures carried out by the central and local governments, such as banning public gatherings, and also the continuous information and precautionary measures delivered by the MOH in Saudi Arabia. The residents' good level of knowledge along with confirmed information (66\%) from various media sources plays an important role in spreading knowledge about the high infectivity of the COVID-19, which can be easily transmitted between people through invisible respiratory droplets.

Grievously, the present study still showed that almost $13.1 \%$ of the residents went to crowded places while more disastrously nearly $60 \%$ did not wear facemasks when leaving their homes. These sensitive behaviors were likely related to both male and female gender, occupation of "students," "Employed Others* (any profession other than healthcare providers)," "Unemployed," marital status of "married," residing in Hail as well as outside in other parts of Saudi Arabia, and participants acquired poor COVID-19 knowledge. The findings of this research come in full agreement with previously published studies [18-20], which indicates that men and late adolescents are more likely to engage in risktaking behaviors. In line with these previous findings, the current study results also suggested a higher correlation between male gender and potentially unhealthy practices toward COVID-19. The higher numbers of residents defined as "Employed other than healthcare providers" going to a crowded place could be attributed to their self-working places. The non-significant but higher numbers risk of not wearing a facemask when leaving their homes in Hail vs. Other residents may be attributed to the less serious situation of the COVID-19 epidemic in a Hail region of Saudi Arabia, resulting in Hail residents assuming that they are at lower risk of infection from the COVID-19 virus. It is worth mentioning that higher COVID-19 knowledge scores were found to be significantly associated with a lower likelihood of negative attitudes toward the COVID-19 epidemic in the current study (Table 4). These results demonstrate the significance of improving residents' COVID-19 information through health education, which may likewise bring about upgrades in their perspectives and practices toward COVID-19. Findings of the demographic factors in this current study associated with KAP toward COVID-19 are generally consistent with the studies published in the past on MERS-COV in 2014 and 2015 [21,22]. These findings further recommended that the health information and education would be increasingly effective in the event with more emphasis on certain demographic groups, for instance, if the health education services are specifically designed for people with a low level of knowledge and awareness, COVID-19 information might be enormously expanded.

One of the limitations of our research is that the findings cannot be generalized to the whole Kingdom because of its small sample size and geographical specificity, mostly in the northern region of Saudi Arabia. Furthermore, because of restricted access to the internet and online information resources, susceptible Saudi population groups under the COVID-19 epidemic, for example, older population and rural dwellers at the grassroot level are bound to have poor information, negative attitudes, and inappropriate preventive practices toward COVID-19. Therefore, KAP toward COVID-19 of vulnerable populations deserves special research attention in the Kingdom of Saudi Arabia. In addition to the limited sample size, the second constraint of the current study is the unstandardized and deficient appraisal of attitudes and practices toward COVID-19, which ought to be established through focus group discussion and in-depth interviews and constructed as multidimensional measures. Because of the time constrain on developing the survey, and due to the very limited time for developing the questionnaire, both attitudes and practices were measured with a few simple questions only.

\section{CONCLUSION}

Our findings suggest that the Saudi population of a relatively high level of socioeconomic status, of both genders, have had good knowledge, optimistic attitudes, and appropriate practices toward COVID-19 during the period of the outbreak's rapid rise. Furthermore, the best COVID-19 information is related to idealistic perspectives and suitable 
practices toward COVID-19, recommending that health education programs planned for improving COVID-19 information are useful for encouraging a hopeful attitude and keeping up safe practices. Ideally, under the consolidated endeavors of the Saudi authorities and every single Saudi occupant, the Kingdom of Saudi Arabia can control this COVID-19 epidemic sooner rather than later. Because of the low sample size, more studies are required to explore the KAP toward COVID-19 among Saudi inhabitants of low financial status.

\section{ACKNOWLEDGMENT}

The authors thank all the participants involved in this study for their cooperation and support. We also thank the Research Ethics Committee at the University of Hail for approving to conduct this research.

\section{AUTHORS' CONTRIBUTIONS}

Farhan Alshammari designed the study and data collection was performed along by Turki Alhagbani. Data analysis was performed by Kashif Ullah Khan and Farhan Alshammari. The manuscript was drafted by Ahmed Dawas Alafnan and Khaled Almansour. The final draft was revised by Kashif Ullah Khan and Farhan Alshammari.

\section{CONFLICTS OF INTEREST}

The authors declare that there are no conflicts of interest.

\section{AUTHORS' FUNDING}

This research did not receive any specific grant from funding agencies in the public, commercial, or not-for-profit sectors.

\section{REFERENCES}

1. Qian GQ, Yang NB, Ding F, Ma AH, Wang ZY, Shen YF, et al. Epidemiologic and clinical characteristics of 91 hospitalized patients with COVID-19 in Zhejiang, China: A retrospective, multi-centre case series. QJM Int J Med 2020;113:474-81.

2. Kotian RP, Faujdar D, Kotian SP, D'Souza B. Knowledge and understanding among medical imaging professionals in India during the rapid rise of the COVID-19 pandemic. Health Technol 2020;2020:1-6.

3. Dilucca M, Souli D. Knowledge, attitude and practice of secondary school students toward COVID-19 epidemic in Italy: A cross Sectional study. BioRxiv 2020;8:236.

4. Sohrabi C, Alsafi Z, O’Neill N, Khan M, Kerwan A, Al-Jabir A, et al. World Health Organization declares global emergency: A review of the 2019 novel coronavirus (COVID-19). Int J Surg 2020;76:71-6.

5. Arab News. Saudi Arabia Announces First Case of Coronavirus Arab News; 2020. Available from: https://www.reuters.com/article/ us-health-coronavirus-saudi/saudi-arabia-announces-first-case-ofcoronavirus-idUSKBN20P2FK.

6. Official Source of Ministry of Interior SPA. Temporary Suspension of Umrah for Citizens, Expatriates Comes as Protection for the Two Holy Mosques' Visitors, Islamic Affairs Minister Says; 2020. Available from: https://www.spa.gov.sa/viewstory.php?lang=en\&newsid=2042982.

7. Reuters World News. Saudi Arabia Suspends Schools, Universities Over Coronavirus Fears; 2020. Available from: https://www.reuters. com/article/us-health-coronavirus-saudi/saudi-arabia-suspendsschools-universities-over-coronavirus-fears-idUSKBN20V0YO.

8. Bloomberg Saudi Arabia. Saudi Arabia Imposes Lockdown in Capital Riyadh, Two Holy Cities: Bloomberg News. Available from: https:// www.bloomberg.com/news/articles/2020-03-25/saudi-arabia-imposeslockdown-in-capital-riyadh-two-holy-cities. [Last accessed on 2020 Mar 25].

9. Official Source of Ministry of Interior SPA. Fine and Imprisonment for Violating Curfew Provisions: Saudi Press Agency SPA; 2020. Available from: https://www.spa.gov.sa/viewfullstory. php?lang=en\&newsid $=2050590$.

10. Center for American Progress HC. Social Distancing To Fight Coronavirus: A Strategy That Is Working and Must Continue: Health Care; 2020. Available from: https://www.americanprogress.org/ issues/healthcare/news/2020/03/25/482278/social-distancing-fightcoronavirus-strategy-working-must-continue.

11. Tang CS, Wong CY. An outbreak of the severe acute respiratory syndrome: Predictors of health behaviors and effect of community prevention measures in Hong Kong, China. Am J Public Health 2003;93:1887-8.

12. Tang CS, Wong CY. Factors influencing the wearing of facemasks to prevent the severe acute respiratory syndrome among adult Chinese in Hong Kong. Prev Med 2004;39:1187-93.

13. Saudi Census Database. General Authority for Statistics: Saudi Census; 2020. Available from: https://www.stats.gov.sa/sites/default/files/arhail-13-01.pdf.

14. Taber KS. The use of Cronbach's alpha when developing and reporting research instruments in science education. Res Sci Educ 2018;48:1273-96.

15. Zhong BL, Luo W, Li HM, Zhang QQ, Liu XG, Li WT, et al. Knowledge, attitudes, and practices towards COVID-19 among Chinese residents during the rapid rise period of the COVID-19 outbreak: A quick online cross-sectional survey. Int J Biol Sci 2020;16:1745.

16. ALdowyan N, Ahmed AS, El-Gharabawy R. Knowledge, attitude and practice (KAP) study about Middle East respiratory syndrome coronavirus (MERS-CoV) among population in Saudi Arabia. Int Arch Med 2017;10:1-12.

17. Asaad AM, El-Sokkary RH, Alzamanan MA, El-Shafei M. Knowledge and attitudes towards Middle East respiratory syndrome-coronavirus (MERS-CoV) among health care workers in South-Western Saudi Arabia. East Mediterr Health J 2019;25:079.

18. Cobey KD, Laan F, Stulp G, Buunk AP, Pollet TV. Sex differences in risk taking behavior among Dutch cyclists. Evol Psychol 2013;11:1474.

19. Duell N, Steinberg L, Icenogle G, Chein J, Chaudhary N, Di Giunta L, et al. Age patterns in risk taking across the world. J Youth Adolesc 2018;47:1052-72.

20. Pawlowski B, Atwal R, Dunbar R. Sex differences in everyday risktaking behavior in humans. Evol Psychol 2008;6:29-42.

21. Almutairi KM, Al Helih EM, Moussa M, Boshaiqah AE, Alajilan AS, Vinluan JM, et al. Awareness, attitudes, and practices related to coronavirus pandemic among public in Saudi Arabia. Fam Community Health 2015;38:332-40.

22. Khan MU, Shah S, Ahmad A, Fatokun O. Knowledge and attitude of healthcare workers about middle east respiratory syndrome in multispecialty hospitals of Qassim, Saudi Arabia. BMC Public Health 2014; $14: 1281$. 